\title{
Recent research on emerging organic electrode materials for energy storage
}

\author{
Tao Huang', Mengqi Long' ${ }^{2}$, Jun Xiao', Hao Liu ${ }^{1,2}$, Guoxiu Wang ${ }^{1}$ \\ 'School of Mathematical \& Physical Sciences, Faculty of Science, University of Technology Sydney, NSW 2007, Australia. \\ ${ }^{2}$ School of Environmental and Chemical Engineering, Shanghai University, Shanghai 200444, China.
}

Correspondence to: Prof./Dr. Hao Liu, School of Mathematical \& Physical Sciences, Faculty of Science, University of Technology Sydney, Sydney PO Box 123 Broadway, NSW 2007, Australia. E-mail: Hao.Liu@uts.edu.au; Prof./Dr. Guoxiu Wang, School of Mathematical \& Physical Sciences, Faculty of Science, University of Technology Sydney, Sydney PO Box 123 Broadway, NSW 2007, Australia. E-mail: Guoxiu.Wang@uts.edu.au

How to cite this article: Huang T, Long M, Xiao J, Liu H, Wang G. Recent research on emerging organic electrode materials for energy storage. Energy Mater 2021;1:100009. https://dx.doi.org/10.20517/energymater.2021.09

Received: 10 Sep 2021 First Decision: 9 Oct 2021 Revised: 21 Oct 2021 Accepted: 24 Oct 2021 Published: 30 Oct 2021

Academic Editors: Yuping Wu, Yuhui Chen Copy Editor: Xi-Jun Chen Production Editor: Xi-Jun Chen

\begin{abstract}
Due to the growth of the demand for rechargeable batteries in intelligent terminals, electric vehicles, energy storage, and other markets, electrode materials, as the essential of batteries, have attracted tremendous attention. The research of emerging organic electrode materials in batteries has been boosted recently to their advantages of low cost, environmental friendliness, biodegradability, and designability. This manuscript highlights and classifies several recent studies on organic electrode materials and lists their potential applications in various battery systems. Finally, the challenge and perspective of organic electrode materials are also summarized.
\end{abstract}

Keywords: Organic electrode materials, batteries, energy storage, low-cost electrode materials, environmentally friendly materials

\section{INTRODUCTION}

With more attention to green energy by society, wind power ${ }^{[1]}$, photovoltaic power ${ }^{[2]}$, tidal power ${ }^{[3]}$ generation are gradually squeezing out of traditional power generation. These power generation systems are unstable, and the power supply and user demand are inconsistent. Thus, power generation systems must be equipped with secondary batteries to store excess electricity ${ }^{[4]}$, leading to increased demand for energy 
storage batteries. There is also growing demand for energy storage batteries in other markets, such as smart electronic devices and new energy vehicles. These smart devices use lithium-ion batteries and polymer lithium-ion batteries, while Uninterrupted Power System and vehicle start-up systems commonly use leadacid batteries ${ }^{[5]}$.

Early batteries were composed of metals with different electrochemically active potentials, such as the famous Voltaic Pile. Later, the battery developed into a rechargeable type. The electrode materials consist of metal oxides, metal salts, metals, etc. $^{[--9]}$, have been applied in rechargeable batteries such as the lead-acid battery $\left(\mathrm{PbO}_{2}-\mathrm{Pb}\right)$, nickel-cadmium battery $[\mathrm{NiO}(\mathrm{OH})-\mathrm{Cd}]$, lithium-ion battery $\left(\mathrm{LiCoO}_{2}-\mathrm{C}, \mathrm{LiFePO}_{4}-\mathrm{C}\right.$, etc.). Most of the electrode materials of these batteries belong to inorganic materials, exhibiting high price, heavy metal toxicity, environmental pollution, and degradable recycling, which need further attention for energy storage applications ${ }^{[10,11]}$. Now, lithium-ion batteries and lead-acid batteries currently have the highest market share ${ }^{[12,13]}$, and lead-acid batteries have achieved a closed loop of production-using-recyclingreproduction. In contrast, lithium-ion batteries have not yet formed an effective market-oriented recycling and reuse program, which leads to serious waste and pollution of electrode materials. Moreover, the resource of cobalt and lithium elements for the fabrication of lithium-ion batteries is unevenly distributed around the world, leading to the unstable cost of electrode materials ${ }^{[1,15]}$.

With the increasing demand for lithium-ion batteries in electric vehicles, subsequent production requires a large amount of lithium ${ }^{[15]}$, cobalt, nickel, manganese, and other elements. At the same time, after the service life of a large number of lithium-ion batteries in electric vehicles expires, there is no effective recycling procedure, and the batteries are directly discarded, causing serious pollution and waste of electrode materials. Therefore, it is crucial to look for novel, low-cost, non-toxic, biodegradable electrode materials that can be designed to meet our needs for next-generation batteries.

Organic electrode materials have changed this situation ${ }^{[16]}$. Organic materials also have oxidation and reduction electrochemical activity and can be used as anode and cathode materials for rechargeable batteries. These materials can be derived from biomass, petroleum industry by-products, etc., regardless of geographical restrictions. The cost of organic electrode materials is affected by the production process. Under the condition of mature and mass production processes, the cost becomes very low. At the end of the battery life, the organic electrode material can be automatically degraded or manually processed into nontoxic and pollution-free substances. At the same time, organic materials can be used in different battery systems by adjusting the length of the carbon chain, functional groups, and other structures. The advantages of emerging organic electrode materials and their applications are summarized as follows.

\section{LOW COST}

The low cost of organic electrode materials allows them to be used in various types of battery systems. Typically, Quinone materials have been successfully used in flow batteries (Huskinson et al. ${ }^{[17]}, 2014$ ). The electrode material was 9, 10-anthraquinone-2, 7-disulphonic acid [Figure 1A], which has a rapid and reversible redox reaction and showed a $0.6 \mathrm{~W} \mathrm{~cm}^{-2}$ at $1.3 \mathrm{~A} \mathrm{~cm}^{-2}$ power density.

Organic cathode materials, along with low-cost anode materials (aluminium, zinc, etc. ${ }^{[18]}$ ), can further reduce battery costs. In 2018, Kim et al. ${ }^{[19]}$ applied a redox-active triangular phenanthrenequinone-based macrocycle [Figure 1B] as cathode material into an aluminum battery. The large triangular structure of the material can allow the reversible embedding and detachment of aluminum ions in the redox reaction. This material has very good electrochemical properties, displaying a high revisable capacity of $110 \mathrm{mAh} \mathrm{g} \mathrm{g}^{-1}$, and a long lifespan of up to 5000 cycles. The electrochemical performances of another two phenanthrenequinone- 
A

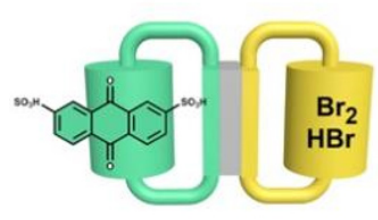

C

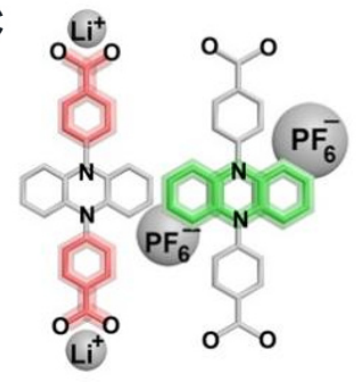

B

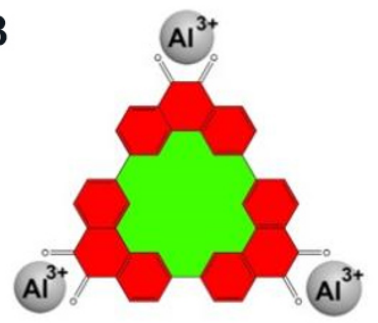

D

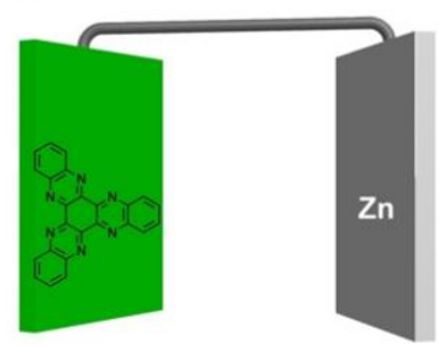

Figure 1. Structure formula of some low-cost organic electrode materials. (A) 9, 10-anthraquinone-2, 7-disulphonic acid for flow battery. (B) A redox-active triangular phenanthrenequinone-based macrocycle. (C) 4, 4 -(phenazine-5,10-diyl) dibenzoate. (D) The phenazine material for Zn-organic battery.

based materials with a monomer and linear trimer structure have also been studied. The triangular macrocycle structure showed the best result because of its layered architecture and the minimization of solvent effects.

In a symmetrical battery system, the low cost of organic electrode materials will be more obvious because the anode and cathode are the same. Dai et al.$^{[20]}$ investigated a dual-ion organic symmetric battery system, which used a molecular anion of 4, 4-(phenazine-5, 10-diyl) dibenzoate [Figure 1C]. For taking advantage of the phenazine and benzoate moieties parts and their electrochemically reversible redox reactions, an artificial bipolar molecular anion was designed and synthesized. The molecular anion had a high average discharge voltage of $2.5 \mathrm{~V}$ and an energy density of $127 \mathrm{Wh} \mathrm{kg}^{-1}$ at $1 \mathrm{C}$ discharge current.

Zinc-organic battery system is another hot area of organic electrode materials. Tie et al. ${ }^{[21]}$ studied a phenazine material [Figure 1D] in the aqueous $\mathrm{Zn}$-organic battery system and got an initial discharge capacity of $405 \mathrm{mAh} \mathrm{g}^{-1}$ at $100 \mathrm{~mA} \mathrm{~g}^{-1}$. The capacity retention was $93.3 \%$ after 5000 cycles at $5 \mathrm{~A} \mathrm{~g}^{-1}$.

Costs of an organic cathode material (p-chloranil) and two common inorganic materials were calculated [Table 1]. P-chloranil is a mature organic material that represents the cost of organic electrode materials when they are mass-produced. P-chloranil has been successfully used to the cathode in aqueous batteries by Yue et al..$^{[22]}$. In his work, the battery uses a p-chloranil material as a cathode and lead as an anode. The pchloranil has a specific capacity of $200 \mathrm{mAh} \mathrm{g}^{-1}$, and the battery discharge voltage platform is around $1 \mathrm{~V}$. Considering the unit price of $\mathrm{p}$-chloranil is $10 \mathrm{CNY}$ (Chinese Yuan) $\mathrm{kg}^{-1[23]}$, its watt-hour cost is:

$$
\frac{10 \mathrm{CNY} \mathrm{kg}^{-1}}{200 \mathrm{Ah} \mathrm{kg}^{-1} \times 1 \mathrm{~V}}=0.05 \mathrm{CNY} \mathrm{Wh}^{-1}
$$


Table 1. Cost per watt-hour comparison of three cathode materials

\begin{tabular}{lll}
\hline Materials & Battery systems & Costs of cathode materials per Wh (CNY) \\
\hline $\mathrm{P}$-chloranil & $\mathrm{P}$-chloranil- $\mathrm{Pb}$ & 0.05 \\
$\mathrm{PbO}_{2}$ (based on raw material lead ingot) & $\mathrm{PbO}_{2}-\mathrm{Pb}$ & 0.06 \\
$\mathrm{LiCOO}_{2}$ & $\mathrm{LiCOO}_{2}$-graphite & 0.22 \\
\hline
\end{tabular}

In the $\mathrm{PO}_{2}-\mathrm{Pb}$ lead-acid battery system, the specific capacity of positive electrode material $\left(\mathrm{PbO}_{2}\right)$ is about $100 \mathrm{mAh} \mathrm{g}^{-1}$, and the battery discharge voltage platform is about $2 \mathrm{~V} .207 .2 \mathrm{~kg} \mathrm{~Pb}$ raw material corresponds to $239.2 \mathrm{~kg} \mathrm{PbO}_{2}$, and the unit price of the lead ingot is $13 \mathrm{CNY} \mathrm{kg}{ }^{-1[24]}$. The unit price of $\mathrm{PbO}_{2}$ (based on raw lead ingots) per watt-hour is:

$$
\frac{13.7 \mathrm{CNY} \mathrm{kg}^{-1} \times \frac{207.2}{239.2}}{100 \mathrm{Ah} \mathrm{kg}^{-1} \times 2 \mathrm{~V}}=0.06 \mathrm{CNY} \mathrm{Wh}^{-1}
$$

In the $\mathrm{LiCoO}_{2}$-graphite lithium-ion battery system, the practical, specific capacity of $\mathrm{LiCoO}_{2}$ is about $140 \mathrm{Ah} \mathrm{kg}^{-1}$, and the battery discharge voltage platform is about $3.8 \mathrm{~V}$. The unit price of $\mathrm{LiCoO}_{2}$ is about

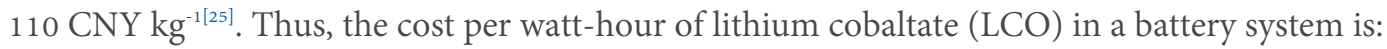

$$
\frac{110 \mathrm{CNY} \mathrm{kg}^{-1}}{130 \mathrm{Ah} \mathrm{kg}^{-1} \times 3.8 \mathrm{~V}}=0.22 \mathrm{CNY} \mathrm{Wh}^{-1}
$$

\section{SAFE AND GREEN}

Organic materials can be designed to be non-toxic and environmentally friendly, which gives them advantages in terms of safety and greenery. As an anode material, zinc is also non-toxic and environmentally benign. Therefore, in addition to the low cost, the organic-zinc battery system is also safe and green, which is very suitable for application in wearable electronic devices. Guo et al. ${ }^{[26]}$ studied a pyrene-4, 5, 9, 10-tetraone [Figure 2A] cathode and zinc anode battery system in a mild aqueous electrolyte. The organic cathode material exhibited a capacity of $336 \mathrm{mAh} \mathrm{g}^{-1}$ and an energy density of $186.7 \mathrm{Wh} \mathrm{kg}^{-1}$, and over 1000 cycles of life.

Biodegradability is another green advantage of organic electrode materials. Because organic materials can be designed into a polypeptide polymer structure, this structure can spontaneously degrade in nature, avoiding the environmental pollution problem. Nguyen et al. ${ }^{[27]}$ synthesized polypeptide materials [Figure $\left.2 \mathrm{~B}\right]$ and designed a metal-free organic radical battery, which showed a capacity of $37.8 \mathrm{mAh} \mathrm{g}^{-1}$. They also studied the degradation and toxicity of the materials, and found the cathode polypeptide was deemed non-toxic towards preosteoblast cells, mouse fibroblast cells, and bovine coronary venular endothelial cells, and could be degraded into small molecules.

Aromatic organic materials contain only carbon and hydrogen elements, without oxygen, nitrogen, sulfur, and other elements. Compared with heavy metals and nitrogenous organic matter, they are less toxic, and some of them are even non-toxic. If the materials are used in batteries, it will be very environmentally friendly. Traditional graphite anode materials also contain only carbon but are currently used only in lithium-ion batteries. The large size of sodium and potassium ions limits the use of graphite in the anode electrode of such batteries, while aromatic organic materials solve this problem. Eder et al. ${ }^{[28]}$ assessed the 

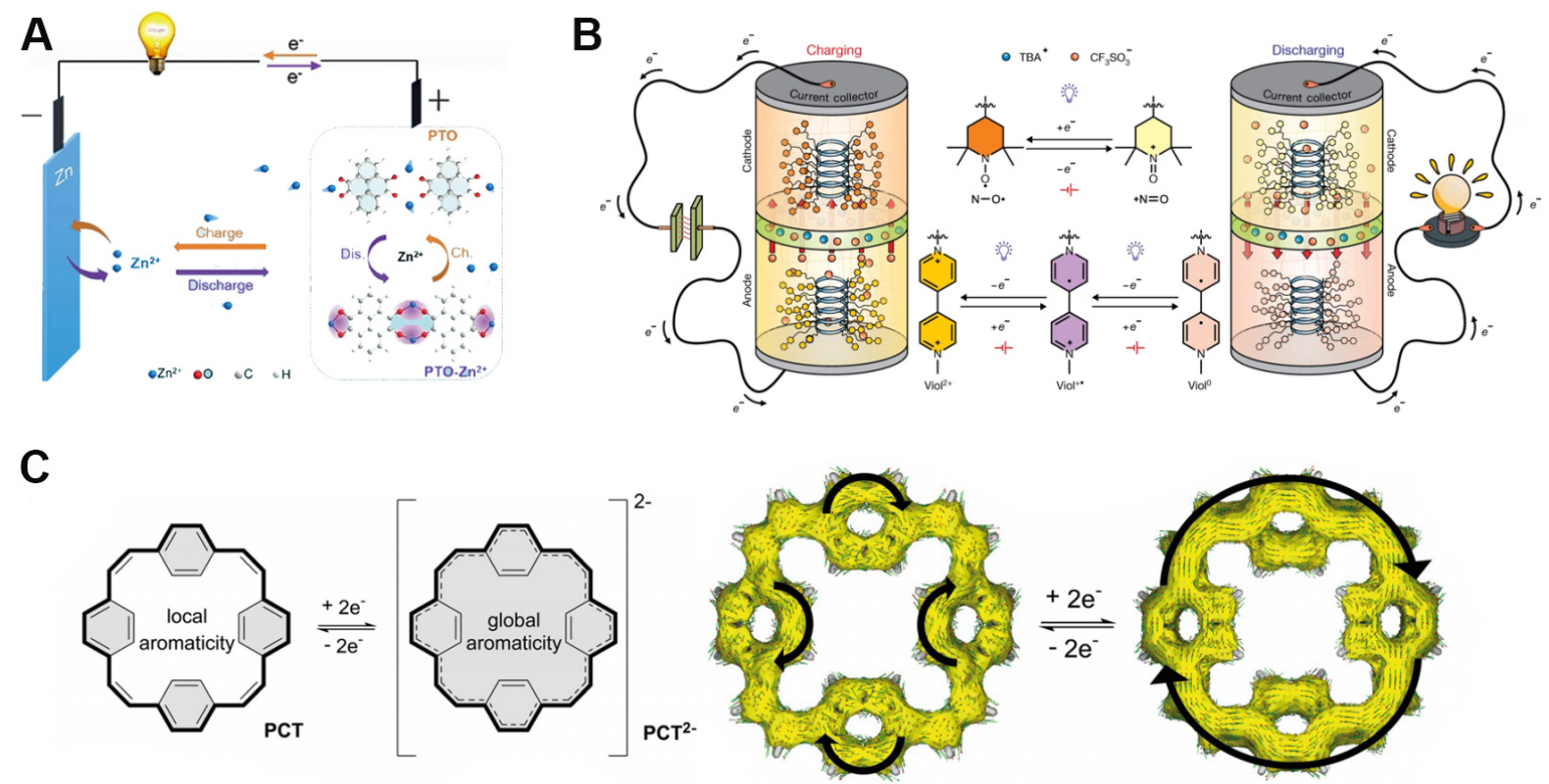

Figure 2. Structural formula of some environment-friendly organic electrode materials. (A) Pyrene-4, 5, 9, 10-tetraone ${ }^{[26]}$. (B) Polypeptide anode and cathode polypeptide materials ${ }^{[27]}$. (C) [2.2.2.2] paracyclophane-1, 9, 17, 25-tetraene ${ }^{[28]}$.

possibility of [2.2.2.2] paracyclophane-1, 9, 17, 25-tetraene [Figure 2C] in sodium-ion batteries, which showed a good potential value.

\section{DESIGNABLE STRUCTURE}

Organic molecules have strong design flexibility by adding and subtracting carbon chains and changing functional groups. These structural changes can alter the electrochemical properties of materials and expand the application fields. In particular, organic electrode materials consist of carbonyl and $\pi$ conjugate structures. The carbonyl group is the site of the REDOX reaction, and the $\pi$ conjugate structure provides high conductivity and overall material stability. For example, when p-benzoquinone and 3, 4, 9, 10perylenetetracarboxylic dianhydride were used as cathode materials, their electrochemical reaction mechanisms are shown in Figure 3A. The mechanism of functional group REDOX of organic materials is different from the interlayer embedding and exhalation mechanism of layered inorganic materials. For example, in sodium-ion batteries and potassium-ion batteries, because the ionic radius of sodium-ion and potassium-ion is much larger than that of lithium-ion, the traditional lithium-ion battery electrode materials cannot be directly applied to sodium-ion batteries and potassium-ion batteries. Organic electrode materials can be directly applied to lithium-ion batteries, sodium-ion batteries, and potassium-ion batteries with the same storage mechanism. Cong et al. ${ }^{[20]}$ investigated the redox performance of four aromatic hydrocarbons, including biphenyl, naphthalene, triphenylene, and phenanthrene [Figure 3B]. The redox potentials of these anode materials were $0.35,0.42,0.45$, and $0.46 \mathrm{~V} v s . \mathrm{K} / \mathrm{K}^{+}$, respectively. It's found that the potassium biphenyl showed the best electrochemical performance as an anode in $\mathrm{K}-\mathrm{O}_{2}$ batteries. By adding the electron-donating methyl group to the benzene ring, the biphenyl redox potential can be reduced from $0.35 \mathrm{~V}$ to $0.29 \mathrm{~V} v s . \mathrm{K} / \mathrm{K}^{+}$.

3, 4, 9, 10-perylene-tetracarboxylic acid-dianhydride (PTCDA) is another organic cathode material used in lithium, sodium, and potassium ion batteries. Tong et al. ${ }^{[30]}$ polymerized PTCDA monomers with different short alkyl chains [Figure $3 \mathrm{C}$ ] and studied their electrochemical properties and redox kinetic differences in potassium-organic batteries. They achieved an energy density of $113 \mathrm{Wh} \mathrm{kg}^{-1}$, power of $35.2 \mathrm{~kW} \mathrm{~kg}^{-1}$, and 
A

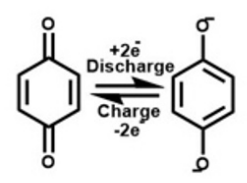

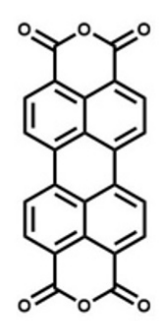
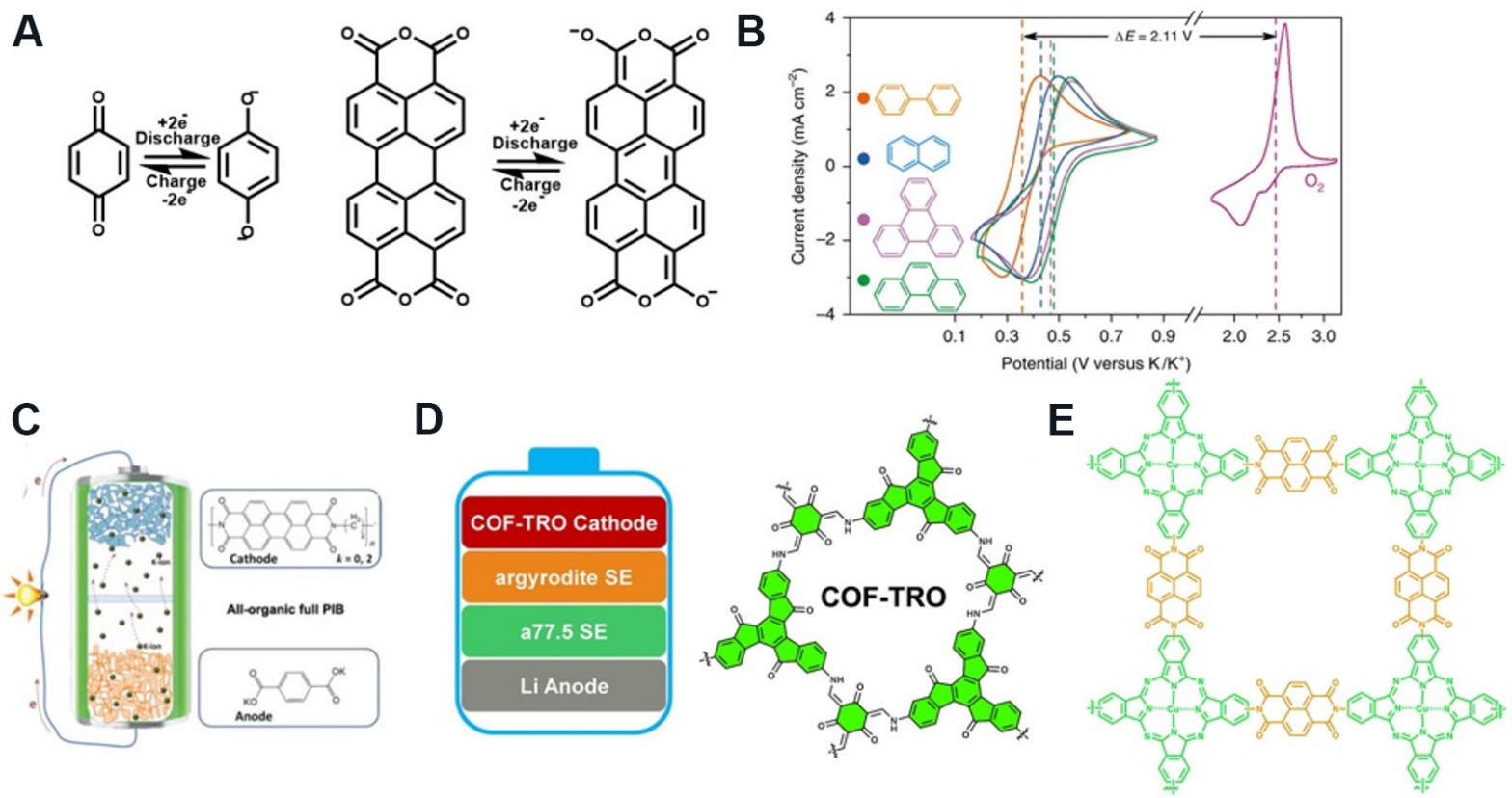

Figure 3. Structural formula and REDOX mechanism of some designable organic electrode materials. (A) REDOX mechanism of pbenzoquinone and 3, 4, 9, 10-perylenetetracarboxylic dianhydride. (B) From top to bottom are biphenyl, naphthalene, triphenylene, and phenanthrene ${ }^{[29]}$. (C) Polymerized PTCDA monomers with different short alkyl chains ${ }^{[30]}$. (D) The truxenone-based covalent organic framework material $^{[31]}$. (E) The conjugated microporous polymers material ${ }^{[32]}$.

excellent performance at an ultrahigh discharge current density up to $147 \mathrm{C}$. The battery capacity loss was near 0 after 1000 cycles at a current density of $7.35 \mathrm{C}$.

Covalent organic framework materials have a tunable chemical structures, which they can be used in different batteries for various purposes. Yang et al. ${ }^{[31]}$ reported a truxenone-based covalent organic framework (COF-TRO) material [Figure 3D] in all-solid-state lithium-ion batteries as the cathode. The material showed a capacity of $268 \mathrm{mAh} \mathrm{g}^{-1}$, and $99.9 \%$ capacity retention after 100 cycles at a $0.1 \mathrm{C}$ rate. The electrode material was synthesized from TRO and 1,3,5-triformylphloroglucinol by polymerization under vacuum heating.

Conjugated microporous polymers (CMPs) materials also have redox-active properties and can be tunable. Wang et al. ${ }^{[32]}$ synthesized and studied the CMPs by integrating copper (II) tetraaminephthalocyanine (CuTAPc) and 1, 4, 5, 8-naphthalenetetracarboxylic dianhydride (NTCDA) units into the RCMPs (CuPcNA-CMP, Figure 3E). They obtained a capacity of $245.3 \mathrm{mAh} \mathrm{g}^{-1}$ at the current density of $0.1 \mathrm{~A} \mathrm{~g}^{-1}$, and $89 \%$ capacity retention after 500 cycles. The rate performance was also outstanding, achieving $125.1 \mathrm{mAh} \mathrm{g}^{-1}$ at $5 \mathrm{~A} \mathrm{~g}^{-1}$. And this electrode material was prepared by the dissolution of CuTAPc and NTCDA into DMAc, and then condensation polymerization under vacuum heating. Similar to covalent organic frame materials, CMPs are also organic polymer materials. Their specific capacities are very similar. The theoretical and practical capacities of the same kind of organic electrode materials depend on the number of REDOX functional groups and the molecular weight of the molecule. Therefore, a higher number of electrochemically active functional groups and lower relative molecular weight usually predict higher specific mass capacity. 


\section{CRYOGENIC SUPERIORITY}

Organic electrode materials have been widely used in cryogenic batteries because of their easy bonding and detachment to protons. Organic materials that have REDOX activity by binding and releasing protons become a good choice for low temperature battery electrode materials. Based on this principle, Tie et al. ${ }^{[21]}$ successfully prepared enhanced zinc-organic batteries with diquinoxalino [2,3-a:2',3'-c] phenazine (HATN) as an electrode material. Tie et al. ${ }^{[33]}$ also summarized the design strategy of a high-performance aqueous $\mathrm{Zn}$ /organic battery. Because aqueous solutions containing acids have a much lower freezing point, and the apparent movement rate of protons in water is very fast, the proton aqueous solution becomes one of the best low temperature electrolytes. Sun et al. ${ }^{[34]}$ studied alloxazine [Figure $4 \mathrm{~A}$ ] material as the anode in aqueous proton battery. This battery delivered a high specific energy density of $110 \mathrm{Wh} \mathrm{kg}^{-1}$ at a power density of $1650 \mathrm{~W} \mathrm{~kg}^{-1}$ at $-60{ }^{\circ} \mathrm{C}$. When the temperature is lower to an extremely low temperature $\left(-90^{\circ} \mathrm{C}\right)$, the material could also exhibit a discharge capacity of $85 \mathrm{mAh} \mathrm{g}^{-1}$.

Another cathode material, p-chloranil, was successfully applied in an ultralow temperature aqueous battery system. Yue et al. ${ }^{[22]}$ reported the p-chloranil [Figure 4B] organic material composite with reduced graphene oxide (PCHL-rGO) used in aqueous Pb-quinone batteries. The Pb/PCHL-rGO batteries exhibited a discharge capacity of $87 \mathrm{mAh} \mathrm{g}^{-1}$ at a current of $0.1 \mathrm{~A} \mathrm{~g}^{-1}$. And the cycle retention was $97 \%$ after 500 cycles at $0.5 \mathrm{~A} \mathrm{~g}^{-1}$ under $-70{ }^{\circ} \mathrm{C}$. This battery system not only has good electrochemical performance at low temperatures, but also is very inexpensive for practical application.

\section{CONCLUSION AND OUTLOOK}

Compared with traditional inorganic electrode materials, organic electrode materials have many advantages in cost, safety, environmental friendliness, design diversity, and low temperature battery applications. On the other hand, organic electrode materials also have disadvantages, mainly in poor conductivity, solubility, and low voltage platform. Researchers are constantly working to overcome these shortcomings.

Not all organic electrode materials conduct electricity well, so many organic electrode materials must be mixed with a large number of conductive carbon materials when used in batteries, which affects the overall volume energy density and mass energy density of the battery. Therefore, it is crucial to enhance the intrinsic electronic conductivity of organic materials so that the electrochemical properties can be boosted. Conjugate $\pi$ structures combined with various functional groups may be an important direction in the future because of their excellent electrical conductivity.

Furthermore, solubility in the electrolyte is another serious problem for organic electrode materials, especially smaller organic monomers. In lithium-ion, sodium-ion, and potassium-ion batteries, organic materials such as small molecules tend to dissolve in the organic electrolyte during charge-discharge cycles. Combining organic materials with a small amount of highly conductive material (such as graphene ${ }^{[15]}$, carbon nanotubes, MXene, etc.) seems to be an effective way to solve the problem of poor electronic conductivity as well as the solubility of the electrode active materials. Polymerization of organic monomers into polymers can also solve the problem of material dissolution, but the method of polymerization needs to be explored by researchers. At present, many polymerization methods use organic solvents, some of which are often expensive or harmful to organisms. Finding a method using water polymerization or solvent-free polymerization has become an effective solution.

Compared with cathode materials such as $\mathrm{LiCoO}_{2}$ and ternary materials, organic cathode materials have a lower voltage platform. Lithium-ion batteries made of $\mathrm{LiCoO}_{2}$ have an open circuit potential above $4 \mathrm{~V}$, while the voltage of most organic lithium-ion batteries is between $2 \mathrm{~V}$ and $3 \mathrm{~V}$. Due to the decrease of the 

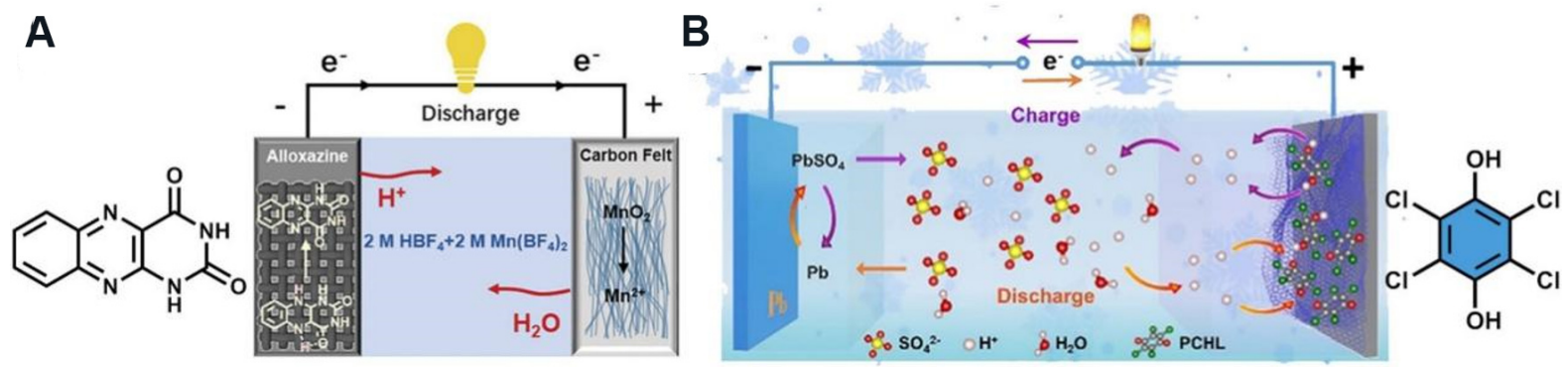

Figure 4. Structural formula of organic electrode materials in cryogenic batteries. (A) Alloxazine ${ }^{[34]}$. (B) P-chloranil ${ }^{[22]}$.

voltage platform, the energy density of the battery decreases, which affects the cost advantage of the application of organic materials in the battery. This requires researchers to develop novel REDOX groups and combine them with organic host structures.

Although there are still many challenges in developing high-performance organic electrode materials, it is no doubt that the electrochemically active organic electrode materials will attract more attention in the future. With the increasing demand for rechargeable batteries, the abandonment of traditional battery materials and environmental pollution problems, and the further reduction of the cost of organic materials, the large-scale application of organic electrode materials in various commercial batteries is promising.

\section{DECLARATIONS}

\section{Acknowledgments}

All authors thank the support from "Joint International Laboratory on Environmental and Energy Frontier Materials" and "Innovation Research Team of High-Level Local Universities in Shanghai".

\section{Authors' contributions}

Selected the topic and conceived the structure of this paper: Huang T, Liu H, Wang G

Searched references and wrote the draft: Huang T, Long M, Xiao J

Polished this manuscript: Liu H, Wang G

The paper was revised by all authors.

\section{Availability of data and materials}

Not applicable.

\section{Financial support and sponsorship}

This project is financially supported by the Australian Research Council (ARC) through the ARC Discovery project (DP180102297, FT180100705).

\section{Conflicts of interest}

Not applicable.

\section{Ethical approval and consent to participate}

Not applicable.

\section{Consent for publication}

Not applicable. 


\section{Copyright}

(C) The Author(s) 2021.

\section{REFERENCES}

1. Jafarzadeh Ghoushchi S, Manjili S, Mardani A, Saraji MK. An extended new approach for forecasting short-term wind power using modified fuzzy wavelet neural network: a case study in wind power plant. Energy 2021;223:120052. DOI

2. Li J, Chen S, Wu Y, Wang Q, et al. How to make better use of intermittent and variable energy? Renew Sustain Energy Rev 2021;137:110626. DOI

3. Ghaedi A, Gorginpour H. Generated power enhancement of the barrage type tidal power plants. Ocean Engineering 2021;226:108787. DOI

4. Dicorato M, Forte G, Pisani M, Trovato M. Planning and operating combined wind-storage system in electricity market. IEEE Trans Sustain Energy 2012;3:209-17. DOI

5. Wang P, Zhu C. Summary of lead-acid battery management system. IOP Conf Ser: Earth Environ Sci 2020;440:022014. DOI

6. Browne MP, Sofer Z, Pumera M. Layered and two dimensional metal oxides for electrochemical energy conversion. Energy Environ Sci 2019;12:41-58. DOI

7. Joshi T, Eom K, Yushin G, Fuller TF. Effects of dissolved transition metals on the electrochemical performance and SEI growth in lithium-ion batteries. J Electrochem Soc 2014;161:A1915. DOI

8. Shukla AK, Ramasse QM, Ophus C, Duncan H, Hage F, Chen G. Unravelling structural ambiguities in lithium- and manganese-rich transition metal oxides. Nat Commun 2015;6:8711. DOI PubMed PMC

9. Liao Y, Chen P, Sun I. Electrochemical study and recovery of Pb using 1:2 choline chloride/urea deep eutectic solvent: a variety of $\mathrm{Pb}$ species $\mathrm{PbSO}_{4}, \mathrm{PbO}_{2}$, and $\mathrm{PbO}$ exhibits the analogous thermodynamic behavior. Electrochimica Acta 2016;214:265-75. DOI

10. Qiu R, Lin M, Qin B, Xu Z, Ruan J. Environmental-friendly recovery of non-metallic resources from waste printed circuit boards: a review. J Clean Prod 2021;279:123738. DOI

11. Bashir S, Adeel M, Gulshan AB, et al. Effects of organic and inorganic passivators on the immobilization of cadmium in contaminated soils: a review. Environmental Engineering Science 2019;36:986-98. DOI

12. Weinert JX, Burke AF, Wei X. Lead-acid and lithium-ion batteries for the Chinese electric bike market and implications on future technology advancement. J Power Sources 2007;172:938-45. DOI

13. Zou C, Zhang L, Hu X, Wang Z, Wik T, Pecht M. A review of fractional-order techniques applied to lithium-ion batteries, lead-acid batteries, and supercapacitors. J Power Sources 2018;390:286-96. DOI

14. Ryu H, Sun HH, Myung S, Yoon CS, Sun Y. Reducing cobalt from lithium-ion batteries for the electric vehicle era. Energy Environ Sci 2021;14:844-52. DOI

15. Huang T, Lu D, Ma L, Xi X, Liu R, Wu D. A hit-and-run strategy towards perylene diimide/reduced graphene oxide as high performance sodium ion battery cathode. Chem Eng $J$ 2018;349:66-71. DOI

16. Schon TB, McAllister BT, Li PF, Seferos DS. The rise of organic electrode materials for energy storage. Chem Soc Rev 2016;45:6345404. DOI PubMed

17. Huskinson B, Marshak MP, Suh C, et al. A metal-free organic-inorganic aqueous flow battery. Nature 2014;505:195-8. DOI PubMed

18. Wang M, Zhang F, Lee C, Tang Y. Low-cost metallic anode materials for high performance rechargeable batteries. Adv Energy Mater 2017;7:1700536. DOI

19. Kim DJ, Yoo D, Otley MT, et al. Rechargeable aluminium organic batteries. Nat Energy 2019;4:51-9. DOI PubMed PMC

20. Dai G, He Y, Niu Z, et al. A dual-ion organic symmetric battery constructed from phenazine-based artificial bipolar molecules. Angew Chem 2019;131:10007-11. DOI PubMed

21. Tie Z, Liu L, Deng S, Zhao D, Niu Z. Proton insertion chemistry of a Zinc-organic battery. Angew Chem Int Ed Engl 2020;59:4920-4. DOI PubMed

22. Yue F, Tie Z, Deng S, Wang S, Yang M, Niu Z. An ultralow temperature aqueous battery with proton chemistry. Angew Chem 2021;133:14001-5. DOI PubMed

23. Raw material purchase website. Spot supply of p-Chloranil: Available from: https://china.guidechem.com/trade/pdetail1654985.html [Last accessed on 26 Oct 2021].

24. Raw material price news. On September 14, 2021, the price of lead was restored in the domestic market. Available from: https://qian.mymetal.net/m/21/0914/11/888208DBE89B0345.html [Last accessed on 26 Oct 2021].

25. Raw material purchase website. Spot supply of lithium cobalt oxide. Available from: https://detail.1688.com/offer/651805024176.html?spm=a261b.12436309.ul20190116.102.17c753829yccbS [Last accessed on 26 Oct 2021].

26. Guo Z, Ma Y, Dong X, Huang J, Wang Y, Xia Y. An environmentally friendly and flexible aqueous zinc battery using an organic cathode. Angew Chem 2018;130:11911-5. DOI PubMed

27. Nguyen TP, Easley AD, Kang N, et al. Polypeptide organic radical batteries. Nature 2021;593:61-6. DOI PubMed

28. Eder S, Yoo DJ, Nogala W, et al. Switching between local and global aromaticity in a conjugated macrocycle for high-performance organic sodium-ion battery anodes. Angew Chem Int Ed Engl 2020;59:12958-64. DOI PubMed PMC

29. Cong G, Wang W, Lai NC, Liang Z, Lu YC. A high-rate and long-life organic-oxygen battery. Nat Mater 2019;18:390-6. DOI PubMed

30. Tong Z, Tian S, Wang H, Shen D, Yang R, Lee C. Tailored redox kinetics, electronic structures and electrode/electrolyte interfaces for 
fast and high energy-density potassium-organic battery. Adv Funct Mater 2019;30:1907656. DOI

31. Yang X, Hu Y, Dunlap N, et al. A Truxenone-based covalent organic framework as an all-solid-state lithium-ion battery cathode with high capacity. Angew Chem Int Ed Engl 2020;59:20385-9. DOI PubMed

32. Wang H, Li Q, Wu Q, et al. Conjugated microporous polymers with bipolar and double redox-active centers for high-performance dual-ion, organic symmetric battery. Adv Energy Mater 2021;11:2100381. DOI

33. Tie Z, Niu Z. Design strategies for high-performance aqueous Zn/organic batteries. Angew Chem Int Ed Engl 2020;59:21293-303. DOI PubMed

34. Sun T, Du H, Zheng S, Shi J, Tao Z. High power and energy density aqueous proton battery operated at $-90{ }^{\circ} \mathrm{C}$. Adv Funct Mater 2021;31:2010127. DOI 